\title{
Effects and safety of intraoperative intermittent pneumatic compression for preventing postoperative venous thromboembolism: a meta-analysis
}

\author{
Yanping Yang, Jianhua Li
}

Department of Nursing, The First People's Hospital of Lianyungang, The Affiliated Lianyungang Hospital of Xuzhou Medical University, Jiangsu, China

Submitted: 5 August 2021; Accepted: 20 November 2021

Online publication: 21 November 2021

Arch Med Sci

DOI: https://doi.org/10.5114/aoms/144091

Copyright $\odot 2021$ Termedia \& Banach

\section{Abstract}

Introduction: Intermittent pneumatic compression (IPC) has been used for venous thromboembolism (VTE) prevention. It is necessary to evaluate the effects and safety of intraoperative use of IPC devices in the prevention of VTE in surgical patients.

Material and methods: Two authors independently searched the PubMed, Cochrane Library, MEDLINE, Embase, China National Knowledge Infrastructure (CNKI), and Wanfang databases for randomized controlled trials (RCTs) and cohort studies on the use of IPC in surgical patients up to June 10, 2021. The Cochrane Collaborations risk of bias tool and the Newcastle-Ottawa Scale (NOS) were used for quality assessment. RevMan 5.3 software was used for statistical analyses.

Results: A total of 13 studies including seven RCTs and six retrospective cohort studies involving 6673 surgical patients were included; 1883 patients underwent IPC intervention. The synthesized RCT results indicated that IPC was beneficial to reduce the incidence of deep vein thrombosis (DVT) (RR = $0.30,95 \% \mathrm{Cl}: 0.22-0.40, p<0.001)$ and VTE $(\mathrm{RR}=0.51,95 \% \mathrm{Cl}: 0.27-0.95$, $p=0.03$ ). The synthesized results from retrospective cohort studies indicated that IPC is beneficial to reduce the incidence of DVT $(R R=0.63,95 \% \mathrm{Cl}: 0.42-$ $0.96, p=0.03)$ and $\mathrm{PE}(\mathrm{RR}=0.34,95 \% \mathrm{Cl}: 0.16-0.72, p=0.005)$. No significant publication bias was found for any synthesized outcomes (all $p>0.05$ ). Conclusions: IPC seems to be safe and effective in the prevention and management of intraoperative VTE. Limited by study sample size, this conclusion still needs to be further confirmed by large-sample, multi-center, high-quality clinical studies.

Key words: intermittent pneumatic compression, surgery, venous thromboembolism, prevention, care.

\section{Introduction}

Venous thromboembolism (VTE) is a common yet potentially life-threatening complication during the perioperative period, including deep vein thrombosis (DVT) and pulmonary embolism (PE). According to previous reports [1, 2], there are more than 698,000 cases of symptomatic DVT and more than 434,000 cases of PE in Europe each year, resulting in more than 543,000 deaths. The incidence of VTE events in Asia is lower than that in European countries [3]. However, with the development of medical diagnostic methods and the strengthening of popula-

\author{
Corresponding author: \\ Jianhua Li \\ Department of Nursing \\ The First People's Hospital \\ of Lianyungang \\ The Affiliated \\ Lianyungang Hospital \\ of Xuzhou Medical \\ University \\ 182 Tongyu North Road \\ Haizhou District \\ Lianyungang \\ Jiangsu Province, China \\ Phone: 12815194604 \\ Fax: 002406811026 \\ E-mail: yzecsk385172@163. \\ com
}


tion awareness, the incidence of VTE is increasing year by year [4, 5]. When a patient presents with DVT, the main manifestations are lower extremity swelling, pain, superficial vein dilation, elevated skin temperature, and restricted activity [6]. If not diagnosed and treated in time, fatal PE may occur, manifested as chest pain, cough, and dyspnea or even death [7]. Therefore, the prevention and treatment of VTE have become a major health problem of global medical workers.

The prevention and treatment of VTE in the perioperative period is of great significance to the prognosis of surgical patients. Intermittent pneumatic compression (IPC) devices use mechanical inflation to compress the veins of the lower limbs to promote blood circulation [8]. Several clinical studies $[7,9]$ have shown that IPC is beneficial to reduce the occurrence of perioperative VTE, promote rapid perioperative recovery, improve the quality of life, and reduce unexpected mortality. However, IPC is currently not widely used in surgery, and due to the limited sample size and different populations, the conclusions drawn by previous studies are different and inconsistent $[10,11]$. Therefore, it is necessary to evaluate the preventive effect of IPC on perioperative VTE by using the method of meta-analysis, to provide evidence-based guidelines for the prevention and treatment of VTE in patients during surgery.

\section{Material and methods}

We aimed to perform and report this systematic review and meta-analysis in compliance with the Preferred Reporting Items for Systematic Reviews and Meta-Analyses (PRISMA) [12].

\section{Study search}

We searched for randomized controlled trials (RCTs) and cohort studies related to the use of IPC in surgical patients, in databases including PubMed, Cochrane Library, MEDLINE, Embase, China National Knowledge Infrastructure (CNKI), and Wanfang. The search strategies were ((intermittent pneumatic compression) OR (IPC) OR (mechanical compression)) AND (intraoperative) OR(surgery) OR (operation)) AND ((venous thrombosis) OR (thromboembolism) OR (deep vein thrombosis) OR (DVT) OR (VTE)). The search time limit is from the establishment of the database to June 10, 2021. The languages of reports were limited to Chinese and English. Additionally, we checked and reviewed the reference lists of associated RCTs and reviews to avoid missing any reports.

\section{Literature inclusion and exclusion criteria}

The inclusion criteria for this meta-analysis were as follows: The type of study was RCT or ret- rospective cohort study on the application of IPC to patients undergoing surgery treatment. The populations of the study were patients $\geq 18$ years of age. The intervention measures covered IPC and the control group, and the cycle and duration of IPC intervention were not limited. The article reported relevant outcome indicators such as the incidence of DVT and PE. The exclusion criteria for this meta-analysis were as follows: case reports, reviews, and observational studies were excluded; related data were incomplete or could not be obtained from contacting the corresponding authors of reports.

\section{Data extraction}

Two researchers independently read and screened the literature according to the inclusion and exclusion criteria. When the opinions were inconsistent, we held a discussion to reach a consensus or the third researcher decided whether to include the study. The content of the literature extraction included the setting, population, sample size, sampling and grouping methods, intervention measures, relevant outcome indicators and research conclusions.

\section{Quality assessment of included studies}

The Cochrane Collaborations risk of bias tool [13] was adopted by two authors independently to evaluate the quality and risk of bias of the included RCTs. Seven specific domains were examined in this tool: sequence generation, allocation concealment, blinding of participants and personnel, blinding of outcome assessment, incomplete outcome data, selective outcome reporting and other issues. Each domain was rated as low risk of bias, high risk of bias or unclear risk of bias according to the judgment criteria. Any disagreements were resolved by discussion and consensus. In addition, we used the Newcastle-Ottawa Scale (NOS) [14] to evaluate the quality of the cohort study. The scale included 8 items with a maximum score of 9 - the higher the score, the higher the quality of the study.

\section{Statistical analysis}

All the statistical analyses were conducted with RevMan 5.3 software. In this present meta-analysis, binary outcomes were presented as Mantel-Haenszel-style risk ratios (RR) with $95 \%$ confidence intervals $(\mathrm{Cl})$. Continuous outcomes were reported as mean differences (MDs). A fixed-effect model was applied in the cases of homogeneity ( $p$-value of $\chi^{2}$ test $>0.1$ and $R^{2}<50 \%$ ), whereas a random-effect model was used in cases of obvious heterogeneity ( $p$-value of $\chi^{2}$ test $<0.1$ and $r^{2} \geq$ $50 \%)$. Publication bias was evaluated using funnel 
plots, and asymmetry was assessed by the Egger regression test. In this study, $p<0.05$ was considered significant.

\section{Results}

\section{Study selection}

The flow chart of study selection is shown in Figure 1 . The initial search identified 128 potentially relevant reports. Of these identified articles, 10 studies were excluded as duplicates. After viewing the titles and abstracts of the 118 remaining studies, the full texts of 41 reports were retrieved. Among them, 28 reports were excluded due to failure to meet the inclusion criteria. Finally, a total of 13 studies [15-27] including seven RCTs $[15,16,21,22,25-27]$ and six retrospective cohort studies [17-20, 23, 24] were included in this meta-analysis.

\section{Characteristics and quality of included studies}

As presented in Table I, of the 13 studies [1527] included in this meta-analysis, a total of 6673 surgical patients were included, and 1883 patients underwent IPC intervention. The types of surgery considered in this meta-analysis included joint replacement, neurosurgery, intracranial surgery, breast surgery, gastrointestinal surgery, and gynecological surgery. As shown in Tables II and III, the quality of the studies included in this meta-analysis were generally good. All studies described and compared baseline data such as age and gender of the two groups of patients; the baseline data between groups were relatively comparable.

\section{Meta-analysis}

The incidence of DVT in the 7 included RCTs $[15,16,21,22,25-27]$ reported the incidence of DVT; there was no significant heterogeneity $\left(R^{2}=\right.$ $40 \%, p=0.13$ ) and a fixed model was applied for meta-analysis. As presented in Figure 2, the synthesized outcome indicated that IPC was beneficial to reduce the incidence of DVT $(R R=0.30$, 95\% Cl: 0.22-0.40, $p<0.001$ )

The incidence of VTE in the 5 included RCTs $[15,16,21,26,27]$ reported the incidence of VTE; there was significant heterogeneity $\left(R^{2}=61 \%, p=\right.$ 0.04 ) and a random model was applied for meta-analysis. As presented in Figure 3, the synthesized outcome indicated that IPC was beneficial to reduce the incidence of VTE $(R R=0.51,95 \% \mathrm{Cl}$ : $0.27-0.95, p=0.03$ ).

The incidence of DVT in the 6 included retrospective cohort studies [17-21, 23, 24] reported the incidence of DVT; there was no significant heterogeneity $\left(I^{2}=28 \%, p=0.23\right)$ and a fixed mod-

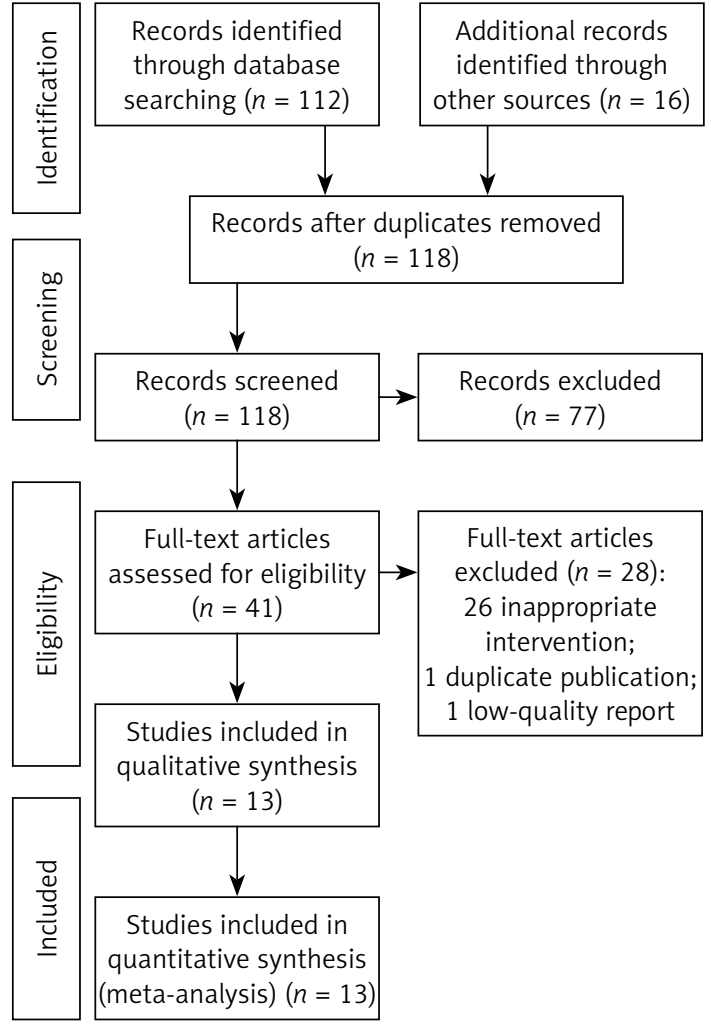

Figure 1. PRISMA flow diagram

el was applied for meta-analysis. As presented in Figure 4, the synthesized outcome indicated that IPC was beneficial to reduce the incidence of DVT ( $\mathrm{RR}=0.63,95 \% \mathrm{Cl}: 0.42-0.96, p=0.03)$.

The incidence of PE in the 3 included retrospective cohort studies [18-20] reported the incidence of PE; there was no significant heterogeneity $\left(I^{2}=0 \%, p=0.89\right)$ and a fixed model was applied for meta-analysis. As presented in Figure 5 , the synthesized outcome indicated that IPC was beneficial to reduce the incidence of $P E(R R=0.34$, $95 \% \mathrm{Cl}: 0.16-0.72, p=0.005)$.

\section{Publication bias}

As presented in Figure 6, the dots were evenly distributed in the funnel plots for synthesized outcomes, and Egger regression tests indicated that there was no significant publication bias for all synthesized outcomes (all $p>0.05$ ).

\section{Discussions}

IPC is currently one of the most widely used VTE physical preventive devices in clinical practice. Although it has been continuously studied in recent years, clinical medical staff still have doubts about its effectiveness and safety [28, 29]. Therefore, it is necessary to further update the evidence regarding the effectiveness and safety of IPC to guide the clinical practice. The results of this meta-analysis have shown that IPC is effec- 


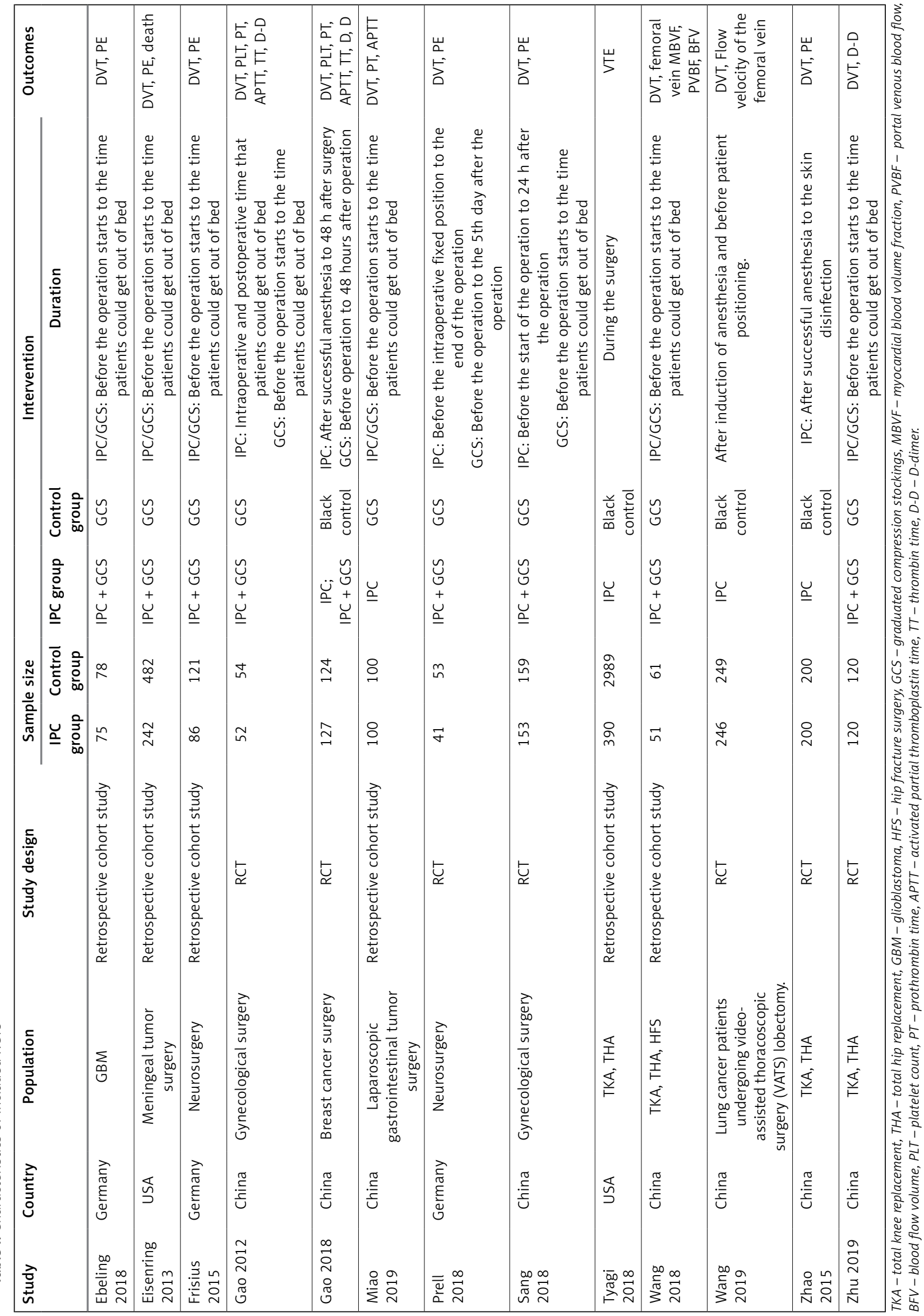


Table II. Quality assessment of included RCTs

\begin{tabular}{|c|c|c|c|c|c|c|c|}
\hline $\mathrm{RCT}$ & $\begin{array}{l}\text { Sequence } \\
\text { generation }\end{array}$ & $\begin{array}{l}\text { Allocation } \\
\text { concealment }\end{array}$ & $\begin{array}{c}\text { Blinding of par- } \\
\text { ticipants and } \\
\text { personnel }\end{array}$ & $\begin{array}{c}\text { Blinding } \\
\text { of outcome } \\
\text { assessment }\end{array}$ & $\begin{array}{c}\text { Incomplete } \\
\text { outcome } \\
\text { data }\end{array}$ & $\begin{array}{l}\text { Selective } \\
\text { outcome } \\
\text { reporting }\end{array}$ & $\begin{array}{l}\text { Other } \\
\text { bias }\end{array}$ \\
\hline $\begin{array}{l}\text { Gao } \\
2012\end{array}$ & $\begin{array}{l}\text { Low risk } \\
\text { of bias }\end{array}$ & $\begin{array}{c}\text { Unclear risk } \\
\text { of bias }\end{array}$ & High risk of bias & $\begin{array}{c}\text { Unclear risk } \\
\text { of bias }\end{array}$ & $\begin{array}{l}\text { Low risk } \\
\text { of bias }\end{array}$ & $\begin{array}{l}\text { Low risk } \\
\text { of bias }\end{array}$ & $\begin{array}{c}\text { Low risk } \\
\text { of bias }\end{array}$ \\
\hline $\begin{array}{l}\text { Gao } \\
2018\end{array}$ & $\begin{array}{l}\text { Low risk } \\
\text { of bias }\end{array}$ & $\begin{array}{c}\text { Unclear risk } \\
\text { of bias }\end{array}$ & $\begin{array}{l}\text { High risk } \\
\text { of bias }\end{array}$ & $\begin{array}{c}\text { Unclear risk } \\
\text { of bias }\end{array}$ & $\begin{array}{l}\text { Low risk } \\
\text { of bias }\end{array}$ & $\begin{array}{l}\text { Low risk } \\
\text { of bias }\end{array}$ & $\begin{array}{c}\text { Low risk } \\
\text { of bias }\end{array}$ \\
\hline $\begin{array}{l}\text { Prell } \\
2018\end{array}$ & $\begin{array}{c}\text { Unclear risk } \\
\text { of bias }\end{array}$ & $\begin{array}{c}\text { Unclear risk } \\
\text { of bias }\end{array}$ & $\begin{array}{l}\text { High risk } \\
\text { of bias }\end{array}$ & $\begin{array}{c}\text { Unclear risk } \\
\text { of bias }\end{array}$ & $\begin{array}{l}\text { Low risk } \\
\text { of bias }\end{array}$ & $\begin{array}{l}\text { Low risk } \\
\text { of bias }\end{array}$ & $\begin{array}{c}\text { Low risk } \\
\text { of bias }\end{array}$ \\
\hline $\begin{array}{l}\text { Sang } \\
2018\end{array}$ & $\begin{array}{l}\text { Low risk } \\
\text { of bias }\end{array}$ & $\begin{array}{c}\text { Unclear risk } \\
\text { of bias }\end{array}$ & $\begin{array}{l}\text { High risk } \\
\text { of bias }\end{array}$ & $\begin{array}{c}\text { Unclear risk } \\
\text { of bias }\end{array}$ & $\begin{array}{l}\text { Low risk } \\
\text { of bias }\end{array}$ & $\begin{array}{l}\text { Low risk } \\
\text { of bias }\end{array}$ & $\begin{array}{c}\text { Low risk } \\
\text { of bias }\end{array}$ \\
\hline $\begin{array}{l}\text { Wang } \\
2019\end{array}$ & $\begin{array}{l}\text { Low risk } \\
\text { of bias }\end{array}$ & $\begin{array}{l}\text { Low risk } \\
\text { of bias }\end{array}$ & $\begin{array}{l}\text { High risk } \\
\text { of bias }\end{array}$ & $\begin{array}{c}\text { Unclear risk } \\
\text { of bias }\end{array}$ & $\begin{array}{l}\text { Low risk } \\
\text { of bias }\end{array}$ & $\begin{array}{l}\text { Low risk } \\
\text { of bias }\end{array}$ & $\begin{array}{l}\text { Low risk } \\
\text { of bias }\end{array}$ \\
\hline $\begin{array}{l}\text { Zhao } \\
2015\end{array}$ & $\begin{array}{c}\text { Unclear risk } \\
\text { of bias }\end{array}$ & $\begin{array}{c}\text { Unclear risk } \\
\text { of bias }\end{array}$ & $\begin{array}{l}\text { High risk } \\
\text { of bias }\end{array}$ & $\begin{array}{c}\text { Unclear risk } \\
\text { of bias }\end{array}$ & $\begin{array}{l}\text { Low risk } \\
\text { of bias }\end{array}$ & $\begin{array}{l}\text { Low risk } \\
\text { of bias }\end{array}$ & $\begin{array}{c}\text { Low risk } \\
\text { of bias }\end{array}$ \\
\hline $\begin{array}{l}\text { Zhu } \\
2019\end{array}$ & $\begin{array}{l}\text { Low risk } \\
\text { of bias }\end{array}$ & $\begin{array}{c}\text { Unclear risk } \\
\text { of bias }\end{array}$ & $\begin{array}{l}\text { High risk } \\
\text { of bias }\end{array}$ & $\begin{array}{c}\text { Unclear risk } \\
\text { of bias }\end{array}$ & $\begin{array}{l}\text { Low risk } \\
\text { of bias }\end{array}$ & $\begin{array}{l}\text { Low risk } \\
\text { of bias }\end{array}$ & $\begin{array}{c}\text { Low risk } \\
\text { of bias }\end{array}$ \\
\hline
\end{tabular}

Table III. NOS quality evaluation of included retrospective cohort study

\begin{tabular}{|c|c|c|c|c|c|c|c|c|c|}
\hline Study & $\begin{array}{l}\text { Repre- } \\
\text { senta- } \\
\text { tiveness } \\
\text { of } \\
\text { exposure } \\
\text { cohort }\end{array}$ & $\begin{array}{l}\text { Selec- } \\
\text { tion of } \\
\text { non-ex- } \\
\text { posed } \\
\text { cohort }\end{array}$ & $\begin{array}{l}\text { Confir- } \\
\text { mation of } \\
\text { exposure }\end{array}$ & $\begin{array}{c}\text { No } \\
\text { disease } \\
\text { before } \\
\text { inclusion }\end{array}$ & $\begin{array}{l}\text { Compara- } \\
\text { bility of } \\
\text { exposed } \\
\text { cohort } \\
\text { and } \\
\text { non-ex- } \\
\text { posed } \\
\text { cohort }\end{array}$ & $\begin{array}{l}\text { Method } \\
\text { of mea- } \\
\text { suring } \\
\text { results }\end{array}$ & $\begin{array}{l}\text { Fol- } \\
\text { low-up } \\
\text { time }\end{array}$ & $\begin{array}{l}\text { Com- } \\
\text { pleteness } \\
\text { of fol- } \\
\text { low-up }\end{array}$ & $\begin{array}{l}\text { Total } \\
\text { score }\end{array}$ \\
\hline $\begin{array}{l}\text { Ebeling } \\
2018\end{array}$ & 1 & 1 & 1 & 1 & 1 & 1 & 1 & 1 & 8 \\
\hline $\begin{array}{l}\text { Eisenring } \\
2013\end{array}$ & 1 & 1 & 1 & 1 & 2 & 1 & 1 & 1 & 9 \\
\hline $\begin{array}{l}\text { Frisius } \\
2015\end{array}$ & 1 & 1 & 1 & 0 & 1 & 0 & 1 & 1 & 6 \\
\hline $\begin{array}{l}\text { Miao } \\
2019\end{array}$ & 1 & 1 & 1 & 1 & 1 & 1 & 0 & 1 & 7 \\
\hline $\begin{array}{l}\text { Tyagi } \\
2018\end{array}$ & 1 & 1 & 1 & 1 & 1 & 1 & 1 & 1 & 8 \\
\hline $\begin{array}{l}\text { Wang } \\
2018\end{array}$ & 1 & 1 & 1 & 1 & 2 & 1 & 1 & 1 & 9 \\
\hline
\end{tabular}

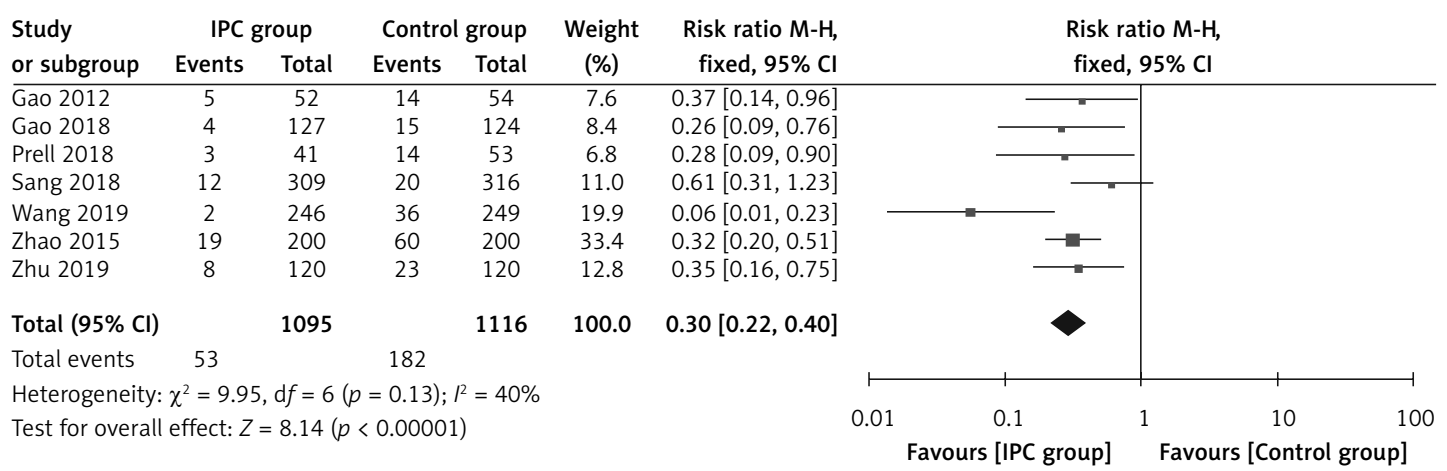

Figure 2. Forest plot for incidence of DVT in the included RCTs 


\begin{tabular}{|c|c|c|c|c|c|c|c|c|c|c|}
\hline \multirow{2}{*}{$\begin{array}{l}\text { Study } \\
\text { or subgroup }\end{array}$} & \multicolumn{2}{|c|}{ IPC group } & \multicolumn{2}{|c|}{ Control group } & \multirow{2}{*}{$\begin{array}{c}\text { Weight } \\
(\%)\end{array}$} & \multirow{2}{*}{$\begin{array}{l}\text { Risk ratio } \mathrm{M}-\mathrm{H} \text {, } \\
\text { random, } 95 \% \mathrm{Cl}\end{array}$} & \multirow{2}{*}{\multicolumn{4}{|c|}{$\begin{array}{l}\text { Risk ratio } \mathrm{M}-\mathrm{H} \text {, } \\
\text { random, } 95 \% \mathrm{Cl}\end{array}$}} \\
\hline & Events & Total & Events & Total & & & & & & \\
\hline Gao 2012 & 5 & 52 & 14 & 54 & 19.0 & $0.37[0.14,0.96]$ & & & & \\
\hline Gao 2018 & 4 & 127 & 15 & 124 & 16.9 & $0.26[0.09,0.76]$ & & & & \\
\hline Prell 2018 & 3 & 41 & 14 & 53 & 15.3 & $0.28[0.09,0.90]$ & & & & \\
\hline Sang 2018 & 12 & 309 & 20 & 316 & 23.8 & $0.61[0.31,1.23]$ & & & - & \\
\hline Zhao 2015 & 19 & 200 & 15 & 200 & 24.9 & $1.27[0.66,2.42]$ & & & - & \\
\hline \multicolumn{2}{|l|}{ Total $(95 \% \mathrm{Cl})$} & 729 & & 747 & 100.0 & $0.51[0.27,0.95]$ & & & & \\
\hline Total events & 43 & & 78 & & & & & & & \\
\hline \multicolumn{7}{|c|}{ Heterogeneity: $\tau^{2}=0.30 ; \chi^{2}=10.13, \mathrm{~d} f=4(p=0.04) ; I^{2}=61 \%$} & 0.05 & 0.2 & 1 & 5 \\
\hline \multicolumn{7}{|c|}{ Test for overall effect: $Z=2.11(p=0.03)$} & & $5[I P C$ & Favou & group] \\
\hline
\end{tabular}

Figure 3. Forest plot for incidence of VTE in the included RCTs

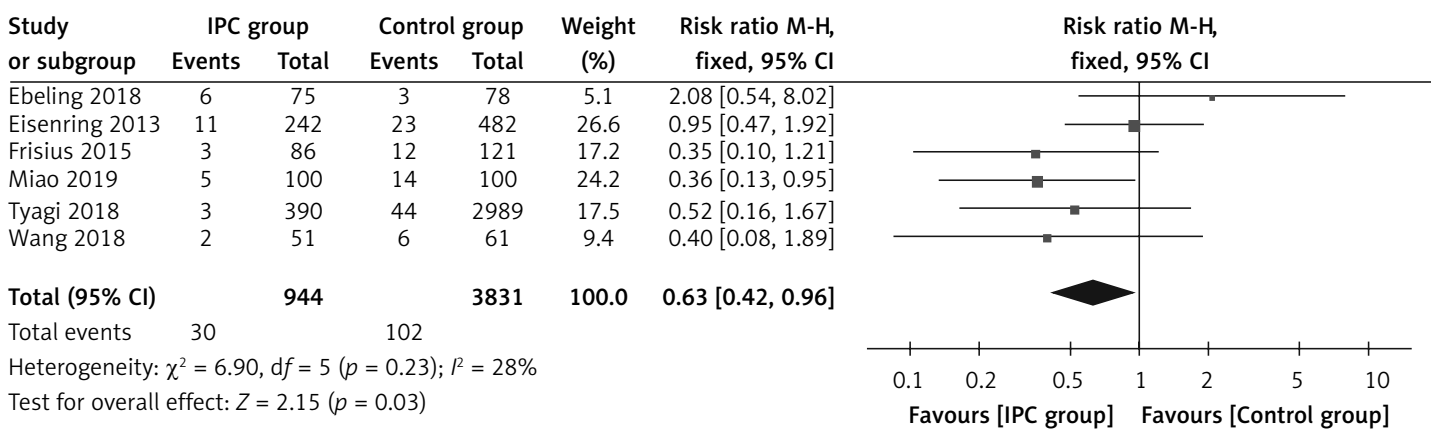

Figure 4. Forest plot for incidence of DVT in the included retrospective cohort studies

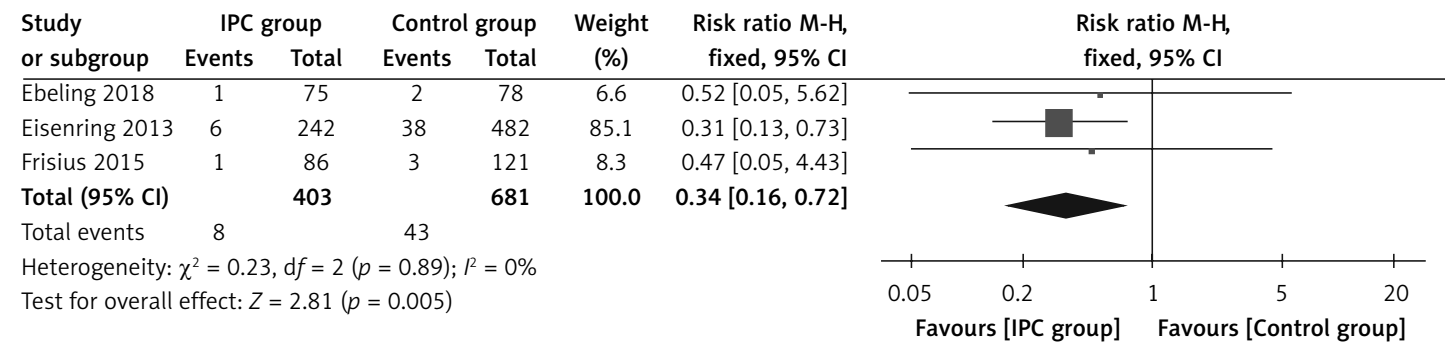

Figure 5. Forest plot for incidence of PE in the included retrospective cohort studies

tive to reduce the risk of DVT, VTE and PE in patients undergoing surgery.

Venous congestion, hypercoagulable state and vascular endothelial injury are recognized as the three major factors for the occurrence of VTE [30]. Surgical patients need to be immobilized for a long time. Surgical injury, the use of drugs such as anesthesia, muscle relaxation, and sedation during the operation put the patient in a highrisk state of thrombosis. Furthermore, intraoperative blood transfusion, hypothermia, laparoscopic pneumoperitoneum, lithotomy and the lying position greatly increase the risk of VTE [31, 32]. IPC is an effective method of thrombosis prevention, which can increase muscle contraction, promote lymphatic and venous blood circulation, and prevent partial accumulation of coagulation factors, thereby effectively preventing the occurrence of VTE. Both IPC and GCS are effective physical prevention methods for DVT [33-35]. Graduated compression stockings (GCS) are designed according to the principle of sequential decompression $[36,37]$. The pressure at the ankle is the highest, and it gradually decreases upwards along the legs, squeezing the veins of the lower extremities, speeding up the return of blood to the heart from the veins of the lower extremities, and reducing blood stasis to prevent dilation of the venous lumen [38, 39]. IPC mainly simulates the contraction and relaxation of lower extremity muscles through intermittent inflation and compression, and squeezes the veins of the lower extremities, thereby speeding up the blood flow of the veins of the lower extremities, avoiding blood pooling in the veins of the lower extremities, promoting venous blood return to the heart, and protecting the function of the venous valve, to achieve the purpose of preventing the occurrence of DVT [40-42].

With the aging of the population, the number of people at high risk of clinical VTE has increased sharply [43]. Therefore, IPC is often used in combination with drugs in order to improve safety. With the widespread use of drugs in clinics, bleeding has become a major clinical concern. This meta-analysis was unable to analyze the bleeding risk of IPC due to the lack of included data. Compared 
A

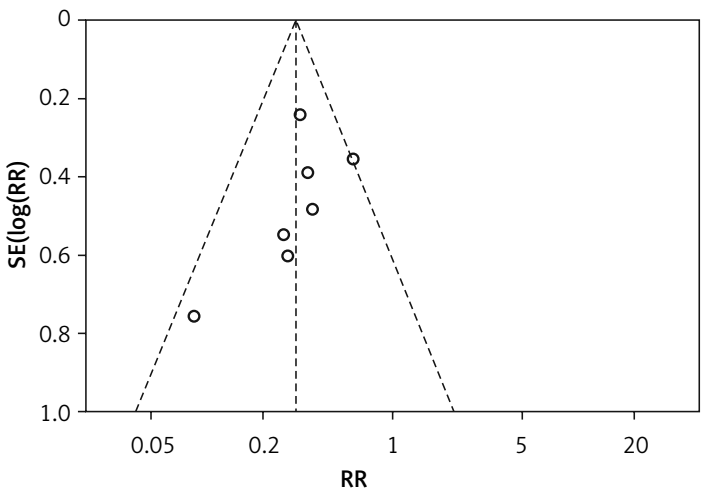

C

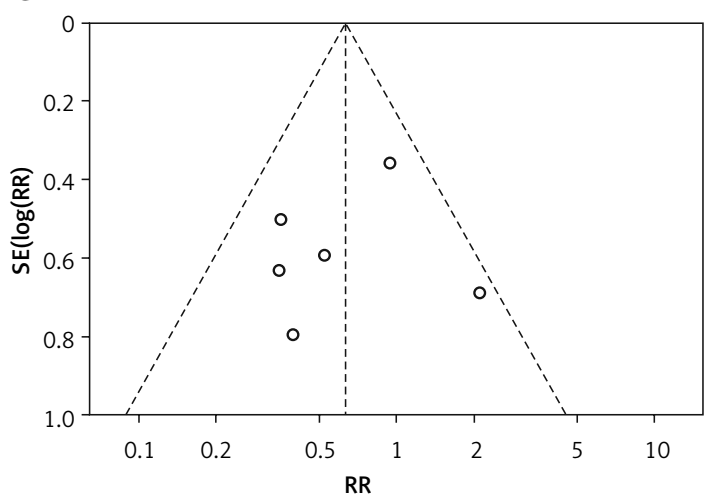

B

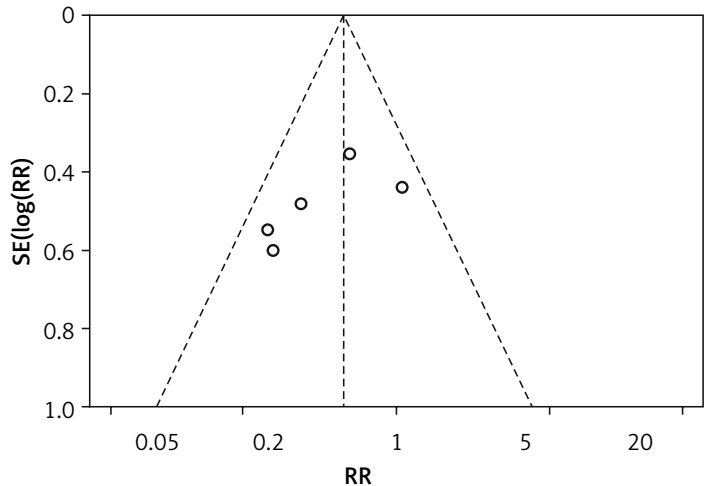

D

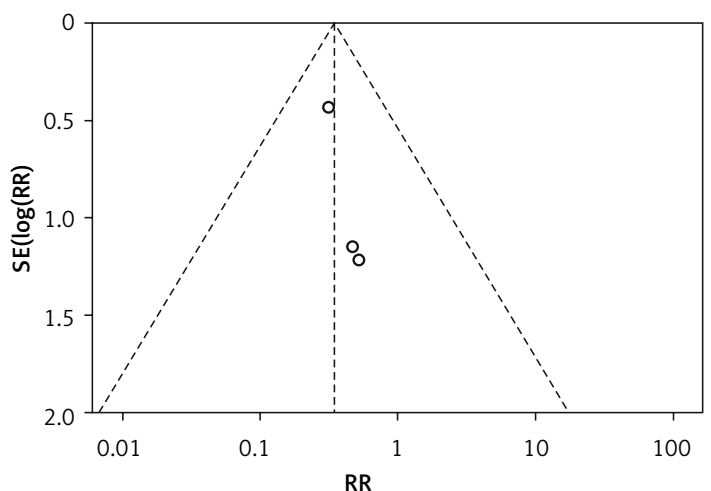

Figure 6. Funnel plots for synthesized outcomes: A - Funnel plot for the incidence of DVT in the included RCTs, B - Funnel plot for the incidence of VTE in the included RCTs, C - Funnel plot for the incidence of DVT in the included retrospective cohort studies, D - Funnel plot for the incidence of PE in the included retrospective cohort studies

with anticoagulants in previous studies [44, 45], IPC can reduce the incidence of bleeding events, but it is not yet possible to draw a certain conclusion on the incidence of major bleeding events and mortality [46]. This may be related to the insufficient number of studies and the different anticoagulants used in the research. Compared with IPC alone, studies have shown that IPC combined with low molecular weight heparin $(\mathrm{LMWH})$ can reduce the incidence of bleeding events. The IPC combined anticoagulant group and the anticoagulant group alone cannot enable a certain conclusion to be drawn on the incidence of bleeding and major bleeding events [47]. It may be related to the heterogeneity between the studies and the insufficient number of studies. Therefore, the safety of use is subject to further analysis in follow-up research.

The results of previous studies $[18,48]$ are different from the results of this study, showing that intraoperative use of IPC will increase the incidence of postoperative DVT. The result may be due to the small sample size and the high risk of DVT in neurosurgery patients. Even if preventive measures are applied, the risk of DVT is still very high. Ultrasound is generally performed when the patient has symptoms after surgery, but a study
[49] showed that more than $50 \%$ of DVTs are invisible and asymptomatic. The reports included in this study come from different populations, and there is a certain degree of heterogeneity in the results, and most included studies did not assess the risk level of VTE during the operation before the preventive measures were given, and there may be insufficient prevention of high-risk patients. All these factors suggest that relevant specialized research is needed in the future to further confirm the effect of intraoperative IPC in surgical patients. At the same time, it is necessary to explore or develop intraoperative VTE risk assessment tools to provide a more scientific basis for the prevention of intraoperative VTE.

Several limitations in this present meta-analysis should be considered. Firstly, the literature included in this study comes from different populations, and there is a certain degree of heterogeneity in the results, and most included studies did not assess the risk level of VTE during the operation before the preventive measures were given, and there may be insufficient prevention of high-risk patients. Secondly, we could not perform subgroup analysis based on the types of surgical procedures limited by collected data; relevant specialized studies are needed in the future to further 
confirm the effect of intraoperative IPC in surgical patients. Also, it is necessary to explore or develop intraoperative VTE risk assessment tools to provide a more scientific basis for the prevention of intraoperative VTE.

In conclusion, the results of this meta-analysis have shown that intraoperative IPC can effectively reduce the incidence of postoperative VTE, and it is worthy of promotion and use in clinical surgery. In view of the relatively small number of RCTs at present and certain clinical heterogeneity in the research population, interventions, and outcome indicators in this meta-analysis, the effectiveness and safety of IPC in surgery still need to be confirmed by multi-center and large-sample clinical studies, to provide reliable evidence-based guidelines for the preventions and management of VTE in surgical patients.

\section{Conflict of interest}

The authors declare no conflict of interest.

\section{References}

1. Hasan SS, Sunter W, Ahmed N, Dawoud D, Zaidi STR. Venous thromboembolism prophylaxis in patients undergoing knee replacements: comparison of real-world outcomes. Int J Clin Pharm 2021; 43: 621-8.

2. Gunning AC, Maier RV, de Rooij D, Leenen LPH, Hietbrink F. Venous thromboembolism (VTE) prophylaxis in severely injured patients: an international comparative assessment. Eur J Trauma Emerg Surg 2021; 47: 137-43.

3. Obi AT, Barnes GD, Napolitano LM, Henke PK, Wakefield TW. Venous thrombosis epidemiology, pathophysiology, and anticoagulant therapies and trials in severe acute respiratory syndrome coronavirus 2 infection. J Vasc Surg Venous Lymphat Disord 2021; 9: 23-35.

4. Kyriakoulis KG, Kokkinidis DG, Kyprianou IA, et al. Venous thromboembolism in the era of COVID-19. Phlebology 2021; 36: 91-9.

5. Danwang C, Bigna JJ, Awana AP, Nzalie RN, Robert A. Global epidemiology of venous thromboembolism in people with active tuberculosis: a systematic review and meta-analysis. J Thromb Thrombolysis 2021; 51: 502-12.

6. Manolis AS, Manolis TA, Manolis AA, Papatheou D, Melita H. COVID-19 infection: viral macro- and micro-vascular coagulopathy and thromboembolism/prophylactic and therapeutic management. J Cardiovasc Pharmacol Ther 2021; 26: 12-24.

7. Yao Y, Xu Q. Progress in the study of cancer-associated venous thromboembolism. Vascular 2021; 29: 408-14.

8. Chibbaro S, Cebula H, Todeschi J, et al. Evolution of prophylaxis protocols for venous thromboembolism in neurosurgery: results from a prospective comparative study on low-molecular-weight heparin, elastic stockings, and intermittent pneumatic compression devices. World Neurosurg 2018; 109: e510-6.

9. Lobastov K, Sautina E, Alencheva E, et al. Intermittent pneumatic compression in addition to standard prophylaxis of postoperative venous thromboembolism in extremely high-risk patients (IPC SUPER): a randomized controlled trial. Ann Surg 2021; 274: 63-9.
10. Zhou J, Li L, Zhen JH, Yan J. Current prophylaxis and treatment of venous thromboembolism in intensive care units of 41 tertiary hospitals of Zhejiang Province. Zhonghua Nei Ke Za Zhi 2021; 60: 139-42.

11. Gomes ET, Assuncao MCT, Lins EM, Puschel VAA. Nursing in mechanical prevention of venous thromboembolism in surgical patients. Rev Esc Enferm USP 2021; 55: e03738.

12. Liberati A, Altman DG, Tetzlaff J, et al. The PRISMA statement for reporting systematic reviews and meta-analyses of studies that evaluate healthcare interventions: explanation and elaboration. BMJ 2009; 339: b2700.

13. Higgins JP, Altman DG, Gotzsche PC, et al. The Cochrane Collaboration's tool for assessing risk of bias in randomised trials. BMJ 2011; 343: d5928.

14. Lo CK, Mertz D, Loeb M. Newcastle-Ottawa Scale: comparing reviewers' to authors' assessments. BMC Med Res Methodol 2014; 14: 45.

15. Prell J, Schenk G, Taute BM, et al. Reduced risk of venous thromboembolism with the use of intermittent pneumatic compression after craniotomy: a randomized controlled prospective study. J Neurosurg 2018: 1-7. doi: 10.3171/2017.9.JNS17533.

16. Sang CQ, Zhao N, Zhang J, et al. Different combination strategies for prophylaxis of venous thromboembolism in patients: a prospective multicenter randomized controlled study. Sci Rep 2018; 8: 8277.

17. Tyagi V, Tomaszewski P, Lukasiewicz A, Theriault S, Pelker $R$. The role of intraoperative intermittent pneumatic compression devices in venous thromboembolism prophylaxis in total hip and total knee arthroplasty. Orthopedics 2018; 41: e98-103.

18. Ebeling M, Ludemann W, Frisius J, et al. Venous thromboembolic complications with and without intermittent intraoperative and postoperative pneumatic compression in patients with glioblastoma multiforme using intraoperative magnetic resonance imaging. A retrospective study. Neurochirurgie 2018; 64: 161-5.

19. Eisenring CV, Neidert MC, Sabanes Bove D, Held L, Sarnthein J, Krayenbuhl N. Reduction of thromboembolic events in meningioma surgery: a cohort study of 724 consecutive patients. PLoS One 2013; 8: e79170.

20. Frisius J, Ebeling M, Karst M, et al. Prevention of venous thromboembolic complications with and without intermittent pneumatic compression in neurosurgical cranial procedures using intraoperative magnetic resonance imaging. A retrospective analysis. Clin Neurol Neurosurg 2015; 133: 46-54.

21. Gao J, Zhang ZY, Li Z, et al. Two mechanical methods for thromboembolism prophylaxis after gynaecological pelvic surgery: a prospective, randomised study. Chin Med J 2012; 125: 4259-63.

22. Mengchun Z, Yujin Y, Chunyan Z. The effect of intermittent inflation compression device combined with sequential compression stockings in preventing deep vein thrombosis after joint replacement. Chin J Gerontol 2019; 39: 4228-31.

23. Suqin M, Dezhen L, Yajun D. Comparison of the effects of intermittent inflation device and medical elastic stockings in preventing deep vein thrombosis in patients undergoing laparoscopic surgery. J Nurs Sci 2019; 34: 36-8.

24. Wang D, Bao F, Li Q, Teng Y, Li J. Semiautomatic intermittent pneumatic compression device applied to deep vein thrombosis in major orthopedic surgery. Biomed Eng Online 2018; 17: 78.

25. Wang X, Song S, Ni R, Lu M, Mao Y. Effectiveness of intraoperative administration of intermittent pneumatic 
compression in preventing deep vein thrombosis in lung cancer patients undergoing video-assisted thoracoscopic surgery lobectomy. J Thorac Dis 2019; 11: 2832-8.

26. Wei G, Songying Z, Wenwen L. Combination of antithrombotic pump and gradient compression stockings to prevent postoperative deep vein thrombosis in breast cancer patients. Chin J Pract Nurs 2018; 34: 1045-9.

27. Yuchi Z, Shudong Z, Mingwei Y. A randomized controlled study on the prevention of deep vein thrombosis of lower limbs after joint replacement with drugs combined with intermittent inflation and compression devices. Chin J Orthop 2015; 35: 1091-5.

28. Zhen KY, Zhai ZG. Progress of intermittent pneumatic compression device application in prevention of venous thromboembolism in inpatients. Zhonghua Jie $\mathrm{He} \mathrm{He} \mathrm{Hu}$ Xi Za Zhi 2020; 43: 599-603.

29. Amanatullah DF, Shah HN, Johnson B, Wall J. Mechanical compression augments venous flow equal to intermittent pneumatic compression. J Orthop Res 2020; 38: 2390-5.

30. Greenall R, Davis RE. Intermittent pneumatic compres sion for venous thromboembolism prevention: a systematic review on factors affecting adherence. BMJ Open 2020; 10: e037036.

31. Fan C, Jia L, Fang F, et al. Adjunctive intermittent pneumatic compression in hospitalized patients receiving pharmacologic prophylaxis for venous thromboprophylaxis: a systematic review and meta-analysis. J Nurs Scholarsh 2020; 52: 397-405.

32. Kakkos SK, Nicolaides AN, Caprini JA. Interpretation of the PREVENT study findings on the adjunctive role of intermittent pneumatic compression to prevent venous thromboembolism. Ann Transl Med 2020; 8: 725.

33. Wang $Y$, Huang $D$, Wang $M$, Liang $Z$. can intermittent pneumatic compression reduce the incidence of venous thrombosis in critically ill patients: a systematic review and meta-analysis. Clin Appl Thromb Hemost 2020; 26 : 1076029620913942

34. Kamachi H, Homma S, Kawamura H, et al. Intermittent pneumatic compression versus additional prophylaxis with enoxaparin for prevention of venous thromboembolism after laparoscopic surgery for gastric and colorectal malignancies: multicentre randomized clinical trial. BJS Open 2020; 4: 804-10.

35. Haykal T, Zayed Y, Dhillon H, et al. Meta-analysis of the role of intermittent pneumatic compression of the lower limbs to prevent venous thromboembolism in critically ill patients. Int J Low Extrem Wounds 2020: 1534734620925391. doi: 10.1177/1534734620925391.

36. Mancini S, Mariani F, Rossi A, Cioncoloni D, Ginanneschi F. Effects of elastic stockings on peripheral and central nervous system. Int Angiol 2020; 39: 155-60.

37. Shalhoub J, Lawton R, Hudson J, et al. Graduated compression stockings as adjuvant to pharmaco-thromboprophylaxis in elective surgical patients (GAPS study): randomised controlled trial. BMJ 2020; 369: m1309.

38. Gianesini S, Raffetto JD, Mosti G, et al. Volume control of the lower limb with graduated compression during different muscle pump activation conditions and the relation to limb circumference variation. J Vasc Surg Venous Lymphat Disord 2020; 8: 814-20.

39. Xu Y, Wang W, Zhen K, Zhao J. Healthcare professionals' knowledge, attitudes, and practices regarding graduated compression stockings: a survey of China's big-data network. BMC Health Serv Res 2020; 20: 1078.

40. Ho KM, Rao S, Nasim S, Rogers FB. Femoral venous catheterisation, lower limb pneumatic compression and venous thromboembolism after severe trauma: a substudy of the da Vinci trial. Anaesth Intensive Care 2021; 49: 74-6.

41. Tang A, Zak S, Lygrisse K, et al. Discontinued use of outpatient portable intermittent pneumatic compression devices may be safe for venous thromboembolism prophylaxis in primary total knee arthroplasty using lowdose aspirin. J Knee Surg 2020. doi: 10.1055/s-00401721092.

42. Chohan A, Abram S, Parkes A, Haworth L, Whitaker JC. Examination of a new mobile intermittent pneumatic compression device in healthy adults. J Wound Care 2020; 29: 370-4.

43. Iyama K, Ikeda S, Inokuma T, et al. How to safely prevent venous thromboembolism in severe trauma patients. Int Heart J 2020; 61: 993-8.

44. Gonzalez Della Valle A, Shanaghan KA, Nguyen J, et al. Multimodal prophylaxis in patients with a history of venous thromboembolism undergoing primary elective hip arthroplasty. Bone Joint J 2020; 102-B (7 Suppl B): 71-7.

45. Tubog TD. Combined intermittent pneumatic leg compression and pharmacological prophylaxis for prevention of venous thromboembolism. Orthop Nurs 2019; 38: $270-2$

46. Arabi YM, Al-Hameed F, Burns KEA, et al. Adjunctive intermittent pneumatic compression for venous thromboprophylaxis. N Engl J Med 2019; 380: 1305-15.

47. Jung YJ, Song KY. Quantifying the added value of low-molecular-weight heparin to intermittent pneumatic compression for preventing venous thromboembolic events under the risk-benefit perspective-reply. JAMA Surg 2019; 154: 271-2.

48. Holleck JL, Gunderson CG. Things we do for no reason: intermittent pneumatic compression for medical ward patients? J Hosp Med 2019; 14: 47-50.

49. Giuliano KK, Pozzar R, Hatch C. Thromboprophylaxis after hospitalization for joint replacement surgery. J Healthc Qual 2019; 41: 384-91. 
Yanping Yang, Jianhua Li 